\title{
Una guerra como destino del exiliado: Londres bajo las bombas según Carles Pi i Sunyer (1888-1971)
}

\author{
Óscar FERNÁNDEZ POZA \\ Universidad Complutense de Madrid \\ oskarfp20@hotmail.com
}

\begin{abstract}
RESUMEN
Aproximación a la literatura memorial en lengua catalana debida a los exiliados de la Guerra Civil española que se encontraron como destino con la Europa de la Segunda Guerra Mundial, en algunos casos como paso previo al exilio en tierras americanas o como definitivo. Atención particularizada a los volúmenes debidos al político catalán Carles Pi i Sunyer: Aquell verd anglès, Vuit escrits d'exili (1939-1941) y Londres en guerra, 1939-1942. Impressions d'un exiliat.
\end{abstract}

Palabras clave: literatura catalana contemporánea, literatura memorial, exilio español y Segunda Guerra Mundial, Carles Pi i Sunyer.

\section{A war as the destination of exile: London under the bombs as Carles Pi i Sunyer (1888-1971)}

\begin{abstract}
Approaching the memorial literature in Catalan due to the exiles of the Spanish Civil War that were found as a destination with the Europe of World War II, in some cases as pre-exile on America or as a final step. Particularized attention to volumes due to the Catalan political Carles Pi i Sunyer: Aquell verd anglès, Vuit escrits d'exili (1939-1941) and Londres en guerra, 1939-1942. Impressions d'un exiliat.
\end{abstract}

Keywords: Contemporary Catalan literature, memorial literature, Spanish exile and World War II, Carles Pi i Sunyer.

\section{Literatura memorial y literaturización de la memoria}

En el presente artículo recuperamos una línea de investigación trabajada en los últimos años, la del exilio y en particular el éxodo de los intelectuales catalanes que tuvieron que abandonar el territorio lingüístico y culturalmente propio tras la con- 
tienda civil española. No pretendemos insistir de nuevo, en estas líneas y como ya nos propusimos en el Congreso Espacios y escrituras del exilio, en la historia de los avatares sufridos en particular por los intelectuales camino del exilio hacia Francia (Fernández Poza y Ribera Llopis 2011: 116) ${ }^{1}$. Para algunos de estos intelectuales supuso un primer paso antes de su posterior salto a Hispanoamérica, en los meses previos o iniciales a la contienda mundial. Ese puede ser el caso de los escritores Avel·lí Artís i Balaguer y el de su hijo Avel·lí Artís-Gener, Anna Murià, Pere Calders o Francesc Trabal; otros como Artur Bladé i Desumvila o Vicenç Riera Llorca realizaron su viaje transatlántico ya con el conflicto iniciado y con Francia ocupada; mientras que otros, tal es el caso de Rafael Tasis i Marca o Carles Fontserè, vivirán la Segunda Guerra Mundial en París. Este último, Carles Fonstserè (2004), por ejemplo y entre otros aspectos, rememora los campos de concentración franceses, la utilización de los republicanos exiliados como carne de cañón, la vida diaria y la animación nocturna del París nazi, la revisión del alcance de la Resistencia francesa o el papel jugado por las élites republicanas en el exilio. Asuntos y situaciones sobre las que también informa a lo largo de diversos capítulos de su volumen Avel·lí Artís-Gener (1975).

Por nuestra parte, en estas páginas y de acuerdo con lo advertido, nos acercaremos a la literatura memorial en lengua catalana por parte de los exiliados de la Guerra Civil española que, en su camino, se encontraron con la Europa de la Segunda Guerra Mundial como destino. Este es el caso de Carles Pi i Sunyer (1888-1971) que nos informa, principalmente, mediante sus escritos relacionados con la guerra continental y en particular sobre su estancia en Londres².

${ }^{1}$ Desde la publicación del artículo han ido apareciendo nuevas aportaciones sobre dicha experiencia por parte de los intelectuales catalanes. Aprovechamos la ocasión para ampliar las noticias bibliográficas allí ordenadas y para hacer hincapié en alguna aportación posterior, en particular las que relacionan exilio y literatura: Maria Campillo, L'exili republicà: política i cultura (Palma de Mallorca: Consell Insular de Mallorca; Barcelona: Publicacions de l'Abadia de Montserrat, 2011); Maria Campillo (ed.) Llegir l'exili (2011); Carlos Guzmán Moncada, Una geografia imaginària: Mèxic i la narrativa catalana de l'exili (Valencia: Tres i Quatre, 2008); Jordi Julià, Poètica de l'exili. L'elegia contemporània en la lírica catalana de postguerra (Palma de Mallorca: Lleonard Muntaner editor, 2011). Queremos hacer mención a una referencia que no ordenamos en aquel momento, se trata del estudio preliminar de Jordi Castellanos a la edición de La ciutat i el tròpic de Lluís Ferran de Pol (Barcelona: Curial, 1985, pp. 5-26). Para conocer más aportaciones a este tema durante el periodo 2009-2014, téngase en cuenta el artículo de J. Font Agulló y J. Gaitx Moltó: «L'exili de 1939. Un estat de la qüestió entre dues commemoracions (2009-2014)». Franquisme \& Transició 2: 231-280.

${ }^{2}$ Carles Pi i Sunyer nació en Barcelona el 29 de febrero de 1888, año en que se celebró la Exposición Universal de Barcelona. Procedía de una familia de la burguesía e intelectualidad catalanas de finales del siglo XIX, siendo su padre médico y catedrático de medicina, en la especialidad de patología general (1883). Entre la II República y la Guerra Civil, ocupó diversos cargos de responsabilidad en los diferentes gobiernos tanto de la Generalitat de Catalunya -la Conselleria de Finances (19321933) y la Conselleria de Cultura (1937-1939)-, como en el Gobierno de Martínez Barrio, el Ministerio de Trabajo (1933-1934), llegando a ser Alcalde de Barcelona $(1934,1936)$. Su exilio pasó por diferentes etapas, una primera en Francia y posteriormente en Londres, donde presidió el Consell Nacional de Catalunya (1941-45), órgano rector de los catalanes exiliados, siendo además miembro del Govern de la Generalitat en el exilio (1945-47). Durante los años del conflicto «trabajó en el Servicio 
Creemos conveniente, antes de continuar y dado que Carles Pi i Sunyer trabaja textos acerca de esa materia que cabe redistribuir en dos formas genealógicas, distinguir entre los dos conceptos que siguen: el de literatura memorial y el de literaturización de la memoria o paso de la memoria por la creación literaria, a través de la ficción, pero con el trasfondo subyacente del hecho real. Por lo tanto y al respecto de esto último, sus muestras se entienden como «textos ficcionales que a través de informaciones extratextuales (paratextos, publicidad, reportajes a los autores, críticas periodísticas) sugieren al lector la conveniencia de una lectura en clave autobiográfica» (Fernández 2003: 1). En tales casos, la voz narradora se constituye en «una entidad $[\ldots]$ que oscila entre una referencia explícita y los juegos de identificación y distanciamiento que permite la ficción» (Fernández 2003: 1); mientras que en la literatura exactamente memorial, la autobiográfica, la voz del narrador «es a la vez una imagen del autor del libro» (Fernández 2003: 3).

A su vez y precisando sobre la literatura memorial que aquí nos interesa, partiendo de las apreciaciones de B. de Riquer en el prólogo a Dues guerres i un exili de Carles Gerhard i Hortet (Riquer 2013: 7-16), podemos plantearnos la posible existencia de tres niveles en las obras memoriales que versan sobre el exilio, atendiendo a un criterio generacional. De acuerdo con ello, distinguimos los siguientes niveles:

-Uno primero, el que corresponde a aquellos intelectuales consagrados, correspondientes con las promociones del Modernisme y el Noucentisme, quienes, ante el inminente fin de la Guerra Civil, se exiliaron y dejaron sus testimonios personales, incluso colectivos, de toda una generación. Podríamos incluir en este grupo las memorias de Josep Maria Francés o las del propio Carles Pi i Sunyer. - Un segundo grupo, el de escritores e intelectuales, que se estaban abriendo camino en las letras catalanas de los años veinte y treinta, y que vieron truncada su producción, aunque nunca la dejaron aparcada a pesar del drama personal que vivieron; generación que contaba a su favor con «una llengua normalitzada que permetia abordar tots els gèneres» (Guillamon 2008: 15). Se pueden destacar las siguientes personalidades: Avel·lí Artís-Gener, Xavier Berenguel, Artur Bladé i Desumvila, Carles Fontserè o Anna Murià ${ }^{3}$.

- Y un tercer grupo, formado por los «records escrits per aquells que durant la Guerra Civil eren uns nens i que després van haver de marxar cap a l'exili» (Riquer 2013: 7). B. de Riquer menciona en este caso diferentes memorias que han ido apareciendo durante la última década y que en nuestra anterior aporta-

Latino Americano de la BBC, y para el Ministerio de Información británico sobre todo prestando colaboración periodística» ( $\mathrm{Pi}$ i Sunyer 1975: 9). En 1952 se estableció definitivamente en Caracas hasta la fecha de su muerte (1971), siendo contratado por el Ministerio de Fomento de aquel país y ejerciendo como profesor de economía en la Universidad Central de Venezuela.

${ }^{3}$ Cuéntese con la siguiente relación de títulos: Xavier Berenguel, Memòries d'un exili: Xile 19401952 (Barcelona: Edicions 62, 1982); Avel·lí Artís-Gener, Viure i Veure (1989-1996); Artur Bladé i Desumvila, De l'exili a Mèxic (Barcelona: Curial, 1993); Carles Fontserè (1999) o Anna Murià, Crònica de la vida d'Agusti Bartra (Barcelona: Martínez Roca, DL, 1967). 
ción no habíamos mencionado. No solo destaca memorias individuales como pueden ser la de los primos Joan y Jacint Reventós, o los títulos de Núria Pi-Sunyer, Cristian Aguadé, Amadeu Cuito Hurtado, Carles Gerhard i Hornet ${ }^{4}$, sino «les diverses experiències vitals que podem trobar en alguns llibres que recullen testimonis col-lectius» (Riquer 2013: 7), como el volumen Veus de l'exili: 20 testimonis de la diàspora catalana $(2007)^{5}$, donde se recogen testimonios como los de Macià Alavedra, Teresa Rovira o Guillermina Peiró.

Antes de acabar este primer apartado, mencionaremos algunas muestras relacionadas con la referida literaturización de la memoria según el género empleado por el autor y, a propósito de lo cual, en el caso de Carles Pi i Sunyer hay que contar con el volumen Aquell verd anglès (1977). Otros ejemplos irían desde la poesía con títulos de Artur Bladé i Desumvila o de Joaquim Amat-Piniella sobre sus vivencias en el campo de concentración de Mauthausen ${ }^{6}$; pasando por el cuento, como puede ser la recreación del viaje hacia su exilio mexicano de Avel·lí Artís i Balaguer en el cuento La reserva (1947) (Fernández Poza 2015: 68-69)7; 1legando a la novela, de la cual, ponemos el ejemplo de L'ombra de l'atzavara (1964) de Pere Calders, título que, como indica el Prof. Castellanos, es «realista o, millor, un text que «obliga» el lector a construir, a través de la lectura, una novel-la «realista», sobre uns materials procedents de l'experiència viscuda, però lleugerament (o no tan lleugerament) desfocalitzats amb l'objectiu, ni més ni menys, de transcendir el realisme» (Castellanos 2011: 224-225) ${ }^{8}$. Valga así mismo el caso de Rosa M. Arquimbau y sus novelas La pau és un interval (1970) y Quaranta anys perduts (1971), en el concierto de las narradoras surgidas en el periodo de entreguerras (v. Madrenas y Ribera 2002).

Un caso curioso son las memorias de Avel·lí Artís-Gener, Viure $i$ veure, que guardan un cierto equilibrio entre ambos conceptos. Para muchos de los miembros de su generación literaria y de su propia familia, y por el carácter irónico heredado de su padre, estas memorias en muchos de sus pasajes son recreaciones o invenciones de la historia; así J. Guillamon (2008: 12) califica el libro, al pasar por algunas escenas acontecidas en tierras mexicanas, como «una transferència emotiva, [que] ens parlen d'un mon familiar, plàcidament acomodat i estable, que potser no va existir mai». No obstante, Avel·lí Artís-Gener tiene otros textos literarios donde litera-

${ }^{4}$ Cuéntese en este caso con la siguiente relación de títulos: Joan y Jacint Reventós, Dos infants $i$ la guerra. Records de 1936-1939 (Barcelona: Club Editor, 1974), o los títulos de Núria Pi-Sunyer i Cuberta, L'exili manllevat (Barcelona: Proa, 2006), Cristian Aguadé, Memòries d'un català a l'exili (Barcelona: La Magrana, 2009), Amadeu Cuito Hurtado, Memòries d'un somni (Barcelona: Quaderns Crema, 2011), Carles Gerhard i Hornet, Dues guerres i un exili: memòries (Barcelona: L'Avenç, 2013).

5 Véase: Josep M. Figueres, Veus de l'exili: 20 testimonis de la diàspora catalana (Valls: Cossentènia, 2007).

${ }^{6}$ Véase: Joaquim Amat-Piniella, Les llunyanies, poemes d'exili (1940-1946) (Barcelona: Columa-L'Albí, 1999) y Artur Bladé i Desumvila Versos de la guerra i de l'exili (Barcelona: Publicacions de l'Abadia de Montserrat, 2007).

7 Véase: Avel·lí Artís i Balaguer, «La reserva» publicado en 1947 en La Nostra Revista (20: 313-315).

${ }^{8}$ Véase también, a propósito de este mismo título, las apreciaciones críticas de M. Campillo (1988: 26). 
turiza más abiertamente la memoria, como es el caso de Les dues funcions del circ (1966) donde rememora su estancia en Fort-de-France mientras sus personajes esperan la reparación del barco, episodio real que ocurrió durante su viaje hacia el puerto de Veracruz, punto de entrada a México para los exiliados españoles (Artís-Gener 1989-1996: III, 82-95; Fernández Poza y Ribera Llopis 2011: 122-123); y también en Paraules d'Opoton el vell (1968) donde utiliza personajes de su exilio mexicano para crear la voz narrativa de su relato (Guillamon 2008: 11-12).

\section{Carles Pi i Sunyer, el exilio y el exiliado a través de sus textos}

Presentado el autor biográficamente en la nota segunda y teniendo que contextualizar su experiencia y sus páginas sobre el exilio en la información histórico-literaria y en la apreciación genealógica precedentes, pasaremos a atender la lectura que de su vivencia como exiliado y del propio exilio en Londres nos ofrece Carles Pi i Sunyer en tres libros. Uno sería el volumen Aquell verd anglès, ya presentado como literaturización de la memoria. Los otros dos, ordenados y editados respectivamente en 1992 por Francesc Vilanova y en 2006 por su hijo, Oriol Pi-Sunyer i Cuberta, son Vuit escrits d'exili (1939-1941) y Londres en guerra, 1939-1942. Impressions d'un exiliat, cuando el exiliado ya se encuentra instalado en Inglaterra. Del primero de los mencionados, como reelaboración de corte más literario, el propio autor nos advierte: «Quan volent rememorar-la reuniu els vostres records, veieu que les hores més felices que us ha ofert són aquelles passades somiant a un parc qualsevol» (Pi i Sunyer 1977: 10). En él entrelaza el paisaje real con el paisaje espiritual fundiéndose en el marco de la vida cotidiana de la Segunda Guerra Mundial (Pi i Sunyer 1977: 12), acercándonos a la primera opción genealógica que se revisaba en el primer apartado de estas páginas.

Pasando por nuestra parte a atender los títulos expresamente memoriales, aprovechemos como, en el prólogo a su volumen La República y la guerra (1970, trad. cast. del autor 1975) que se viene presentado como memorias de un político catalán y donde el autor abarca la época de la República y la Guerra Civil, Carles Pi i Sunyer informa que tenía «escritos diez volúmenes de Memorias [...] Son cuartillas escritas al estímulo del recuerdo, que podrán tener interés personal para mí, pero que probablemente no lo tengan para los demás» (Pi i Sunyer 1975: 11).

Todo ese material se ha ido reorganizando en diferentes libros que han ido apareciendo gracias a la labor, primero, del propio autor y posteriormente por sus descendientes y la Fundación que lleva su propio nombre. En La República y la guerra recoge sus experiencias vitales durante el ciclo señalado y que él considera «de perdurable interés recordar sobre aquel período de tanto relieve histórico como es el de la República y la guerra que tuvimos que hacer para defenderla» (Pi i Sunyer 1975: 11-12), narrando los hechos vividos durante aquel periodo, con el proyecto de cambiar un Estado (Pi i Sunyer 1975: 12), y con los avatares finalmente dramáticos del conflicto civil. Con ese pensamiento de Carles Pi i Sunyer como telón de fondo, nos centraremos en los dos textos ya citados, Vuit escrits d'exili (1939-1941) y Londres en guerra, 1939-1942. Impressions d'un exiliat. Cabe apreciar que entre la cronolo- 
gía recogida en aquel primer volumen memorial y la de estos otros dos, tercia la experiencia intermedia de la salida del país, cuya información a partir de textos del autor se ha ordenado en el volumen 1939: memòries del primer exili (2000). Acerquémonos, por tanto, al Pi i Sunyer que ha dejado atrás España y Cataluña y que encara la guerra subsiguiente desde Londres a partir de la noticia sobre la invasión alemana de Polonia el día 1 de septiembre de 1939 (Pi i Sunyer 2006: 37-40).

En el prólogo al segundo volumen mencionado de entre los dos aquí atendidos, O. Pi-Sunyer i Cuberta (2006: 9) lo califica como unas «notes de camp», recogiendo la idea mencionada por su padre y destacada por nosotros con anterioridad. Estas notas tienen un valor testimonial, «però també ens poden ajudar a entendre més a fons les formes de la vida i del pensament dels anglesos» (Pi-Sunyer i Cuberta 2006: 10). Por su parte, el primero de aquellos volúmenes lo constituyen escritos donde el autor reflexiona en su exilio sobre el papel de «Catalunya en aquest context convulsionat», según F. Vilanova (1992: 7). De esta edición de los papeles personales del autor, nos valdremos de tres de su textos -La significació del moment, Més val tenir raó que no pas guanyar y No hi aneu!-, aquellos que tienen de trasfondo la Segunda Guerra Mundial y «uns protagonistes, els catalans de l'exili o els de l'interior» (Vilanova 1992: 10). La información extraída de esta fuente, se incorporará en el momento en que sea oportuno a los contenidos que se vayan extrayendo del segundo de los volúmenes, el editado por O. Pi-Sunyer i Cuberta, que tomamos como hilo conductor de lo que pasamos a exponer.

Carles Pi i Sunyer se exilia «en un país [...] que inicialment no coneixia gaire [...]. S'hauria d'entendre aquesta llacuna lingüística i cultural [...] com un artefacte del seu temps» (Pi-Sunyer i Cuberta 2006: 9-10). Habrá que recordar, que tanto a nivel cultural como literario, la sociedad catalana, en su gran mayoría, estaba más próxima al modelo francés que al anglosajón. Nuestro autor, además, llega a un Londres previo al estallido del conflicto con Alemania, aunque la sociedad inglesa ya sentía el «perill imminent» (Pi-Sunyer i Cuberta 2006: 21-22), como reflejan en sus notas, las cuales van desde «just abans que esclatés la guerra fins el primers mesos de 1942: la primera meitat d'una guerra de cinc anys, un període de successives decepcions i derrotes més que campanyes exitoses» (Pi-Sunyer i Cuberta 2006: 22).

Ante ese espectro y como indica O. Pi-Sunyer i Cuberta, su padre pasa de observador a participante activo, haciendo patente que «volia aportar-hi el seu granet de sorra («doing his bit»)» (Pi-Sunyer i Cuberta 2006: 33), como el propio autor explicaba en otro libro hecho de recuerdos ingleses, Aquell verd anglès (1977), pues «des de la primera hora vaig sentir amb la gent anglesa una mena d'afinitat espiritual...; em trobava en el punt més destacat, un lloc d'observació de primera línia per a veure i procurar comprendre les commocions que sacsejaven el mon» (Pi i Sunyer 1977: 9).

En consonancia con ello, va documentando la vida cotidiana londinense, de acuerdo con la expresión inglesa carrying ${ }{ }^{9}$, «una tenacitat que li negava a l'enemic la satisfacció de poder trencar l'ordre normal de la vida civilitzada» y «fent vida quotidiana com si tot fos normal, mal grat la violència i la perpètua crisi superfi-

9 Carles Pi i Sunyer dedica una nota para explicar este concepto (Pi i Sunyer 2006: 121-123). 
cials» (Pi-Sunyer i Cuberta 2006: 32). Un ejemplo es su primer texto, el ya mencionado del 1 de septiembre de 1939, donde nos presenta una ciudad y una sociedad inglesas que no se muestran preocupadas, aunque sí están preparadas ( $\mathrm{Pi}$ i Sunyer 2006: 43-44), dada la guerra que ya sufre el viejo continente:

el nostre carrer, força apartat del tràfec, no es veuen encara els senyals de la inquietud del dia. Afinant-ho molt, una soledat major que l'acostumada, la manca de les colles de criatures que normalment juguen i esvaloten a l'aire lliure, alguna mestressa de casa que enganxa tires de paper als vidres o posa cortines negres a les finestres, un auto on són encabides un munt de maletes i mantes enrotllades. (Pi i Sunyer 2006: 37)

A partir de aquí el autor va describiendo una ciudad en plena actividad, con el trasiego de sus habitantes de un lugar a otro, los movimientos estratégicos de los soldados ${ }^{10}$..., mostrando la normalidad de la vida diaria a lo largo y ancho de los diferentes lugares de la ciudad (Pi i Sunyer 2006: 38-39; 66-67; 146) ${ }^{11}$, al tiempo que hace referencia al mantenimiento de los oficios religiosos (Pi i Sunyer 2006: 9699) ${ }^{12}$; o a la reconstrucción de la ciudad tras un bombardeo (Pi i Sunyer 2006: 151, $154-155$; 156-158; 166-168).

La normalidad de la ciudad y de sus habitantes, Carles Pi i Sunyer solo la interrumpe mediante descripciones de hechos que son provocados, en sí mismos, por la guerra, dedicándoles una nota a cada asunto: el uso de las máscaras de gas, empleadas por cualquier miembro de la sociedad ( $\mathrm{Pi}$ i Sunyer 2006: 47-48), las sirenas antiaéreas (Pi i Sunyer 2006: 49), los preparativos para un posible bombardeo (Pi i Sunyer 2006: 54), las noticias del avance de la contienda (Pi i Sunyer 2006: 56; 8385), la llegada de refugiados (Pi i Sunyer 2006: 100-104, 111-113) o el racionamiento de los alimentos (Pi i Sunyer 2006: 105-110). Con todo, hay que destacar como, dentro de esa anormalidad, el autor no solo incluye sino que insiste en la descripción de escenas cotidianas (Pi i Sunyer 2006: 57), en algunos casos con cierto tono lírico (Pi i Sunyer 2006: 67), tal y como puede ser un encuentro de dos enamorados,

absorts a mirar-se i contents de sentir-se junts. Abandonades al costat hi ha les dues caixetes. De primer, potser els donaren motiu de conversa: qui sap si han volgut mirar-se, grotescs, amb la carota de goma i ulleres de mica. Potser hauran rigut, potser hauran sentit una esgarrifança estranya en veure's tan lletjos. Però ara semblen haver-se'n oblidat. (Pi i Sunyer 2006: 48)

10 Véase también en Aquell verd anglès (Pi i Sunyer 1977: 27, 94-95, 97-98, 102, 112-113)

11 En el prólogo Josep Pi-Sunyer i Cuberta a Aquell verd anglès, su autor comenta que es un libro de «impressions sobre el verd dels parcs anglesos [que] sobrepassen de molt el sentit físic d'una descripció, atès que copsen més que res el sentiment anímic dels parcs, de la seva dolçor, la gent que s'hi esplaia hi reposa, la pau que els envolta i el seu redós de refugi, de recolliment i de repòs» (Pi i Sunyer 1977: 7).

12 Véase también en Aquell verd anglès (Pi i Sunyer 1977: 21), así como noticias sobre prácticas deportivas (Pi i Sunyer 1977: 20-21, 40, 100-101, 140). 
A partir de la visión del autor de estas escenas, podemos observar tres grandes temas que van apareciendo en sus notas: la transformación de la ciudad de Londres, la comparación con la Guerra Civil española y la cultura en tiempo de guerra.

Carles Pi i Sunyer nos describe la transformación de la capital británica desde las primeras líneas, pasando de una ciudad llena de vida y sin muchos signos de la inminente actividad bélica a presentarnos signos suyos en unos pocos días ( $\mathrm{Pi}$ i Sunyer 2006: 59-63; 70-71). Valga como ejemplo la incorporación de los refugios antiaéreos (Pi i Sunyer 2006: 63-65) y de los sacos de arena al espacio urbano, como

en una decoració de teatre que conservés el mateix teló de fons, però en la qual s'haguessin posat uns bastidors i primers plans de tramoia, així també, a qualsevol que sigui el lloc cap on girem l'esguard, sempre hi trobem la visió escenogràfica dels munts de sacs terrers [...] Els munts de sacs que apuntalen els edificis, que tapen aparadors i finestres, que fan com un glacis de protecció al davant de les portes, que cobreixen els monuments, que formen petits refugis per als guàrdies a les cruilles dels carrers. Construccions senceres, sòlides fortaleses, catedrals atrevides, formades per sacs, parets, murs, fonaments, terraplens, talussos, contraforts, voltes; [...] una gran multiplicitat de petites arquitectures com les que fèiem quan érem nens amb les fustes de les caixes de construccions de joguina. (Pi i Sunyer 2006: 59-60).

Esos cambios urbanos (Pi i Sunyer 2006: 129) se evidencian con la llegada de los bombardeos y sus efectos en los edificios y en los habitantes, entonces ya la «guerra està pròxima, immediata, present; ronda el cel en les lluites èpiques entre els avions, baixa a la terra amb la destrucció de les bombes» (Pi i Sunyer 2006: 86). Se puede hablar de que este tema se encuentran en quince notas, de las cuales se desprenden tres asuntos: el de los bombardeos, en sí mismos, el de los refugios y el de los bomberos. Además hay dos notas que engloban el tema: Aviadors. Els pocs als qui tants deuen tant (Pi i Sunyer 2006: 91-95) y La coratjosa gent de Londres (Pi i Sunyer 2006: 239-247). El primero, a través de una prosa lírica, trata sobre la Batalla de Inglaterra y el segundo cierra esta secuencia dando las fechas de los diferentes bombardeos sufridos por el pueblo inglés, al tiempo que realiza una alabanza de la población londinense (Pi i Sunyer 1992: 65-66).

Los bombardeos y los efectos en la ciudad se recogen en los siguientes títulos: El viatge en autobús, L'aprenentatge del bombardeig, Reportatge dels primers bombardeigs, La ciutat ferida, El Londres vell, L'alliberament del maniquí, La tristesa humil, "Volia veure les destrosses...», Tornem a la City, Impressions del moment y Psicologia del bombardejat. A través de sus viajes en transporte público, el autor va narrando sus impresiones sobre la destrucción de la ciudad, «des dels afores al centre en el moment del raid, i copsar com un fotomuntatge d'impressions que se superposen i donen un quadre sintètic de la ciutat quan comença a fer l'aprenentatge dels primers bombardeigs» (Pi i Sunyer 2006: 141); al mismo tiempo nos presenta la actitud de los londinenses, dispuestos a seguir con sus ocupaciones diarias. En ocasiones se trata de una ciudad aparentemente sin vida, «una ciutat encantada», «una ciutat de nit amb llum de dia» (Pi i Sunyer 2006: 141), la del extrarradio, pero cuando llega a la city se encuentra una urbe llena de activi- 
dad, Oxford Street, Hyde Park ${ }^{13}$ o Victoria Station (Pi i Sunyer 2006: 143-145), a favor de lo cual opera la voluntad del pueblo de Londres.

No obstante, a pesar de todo y según van creciendo sus notas, Carles Pi i Sunyer nos presenta una ciutat ferida, donde las ruinas «són vulgars i lletges [...] No tenen el prestigi romàntic de les columnates clàssiques o les velles pedres gòtiques». Esa destrucción pasa por el filtro del escritor observador, a quien aquel escenario le produce «una emoció profunda i penosa» (Pi i Sunyer 2006: 150) ${ }^{14}$, en medio de la cual el

dolor prové de veure cruelment destrossats aquells llocs que tan d'interès tenen per a nosaltres, el monuments tradicionals, les pedres venerables, els bells edificis que resistiren la injúria del temps i ara sofreixen de la fúria dels homes [...] És com una amputació, un esquinç de la nostra vida íntima. I aquesta impressió ens la fa sobretot la visió de les cases convertides en munts d'enderrocs, amb la lletjor de les desferres polsoses, els interiors desfets i la intimitat violada. (Pi i Sunyer 2006: 150)

Esa destrucción le obliga transitar por aquella urbe bombardeada cada día por un recorrido distinto, descubriendo rincones que antes no conocía, recreando una nueva «topografia de les comunicacions»,

uns trajectes absurds i precaris, a través d'un laberint de carrers estrets, entre cartells i sagetes que van indicant la via intricada i sinuosa. Un corrent cabalós de trànsit omple, embussa o obtura aquestes petites i modestes artèries, i sembla que mai podria endegarse si no fossin els policies, amb una flegma impertorbable que ni la inquietud de l'hora rosega, qui van a poc a poc donant-hi sortida. I a poc a poc va escolant-se la riuada de moviment per aquestes vies que en temps normals deuen ésser quietes i gairebé desertes, i us sorprèn veure sortir els massissos autobusos d'uns carrerons estrets, en els quals semblen extraviats i perduts i pels quals no haurien d'haver passat mai. (Pi i Sunyer 2006: $152-153)^{15}$

Un ejemplo de esa ciutat ferida a la que le llevan esos sorprendentes recorridos puede ser la descripción de los alrededores de la catedral de San Pablo, donde «el foc ha donat a les pedres una entonació d'or vell, que recorda la pàtina que el sol dels segles posà en els carreus dels amfiteatres romans» (Pi i Sunyer 2006: 174175); o, en La tristesa humil, cuando nos muestra la destrucción de un barrio donde no existen infraestructuras que justifiquen el bombardeo,

\footnotetext{
13 Véase también Aquell verd anglès (Pi i Sunyer 1977: 89-109).

14 Véase también en la nota Impressions del moment del volumen Londres en guerra... (Pi i Sunyer 2006: 178-180).

15 Véase también en la nota Impressions del moment del volumen Londres en guerra... (Pi i Sunyer 2006: 181-182). La urbe caótica de la cita anteriormente sangrada, contrasta con la descripción rectilínea que realiza del parque de Clapham Common en el volumen Aquell verd anglès: «us fa la sensació del camp lliure. Però el terreny que ocupa és en realitat dividit en parcel·les destinades a funcions diverses i adequadament arranjades per a servir-les. Aquesta ordenació, que sembla espontània i no forçada, és com un transsumpte de la naturalitat dirigida de la vida anglesa» (Pi i Sunyer 1977: 19).
} 
munts de runes i estelles, sostres foradats, portes sense batents, finestres sense vidres. Una de les cases ha quedat tallada i es veuen les habitacions interiors, els pisos i els envans com en la secció d'un gravat d'un llibre tècnic d'arquitectura. Romania encara, enganxada a la paret, el marc d'una senzilla xemeneia, uns mobles polsosos, l'ampliació fotogràfica d'un antic retrat de família. [...] Els interiors oberts deixen veure la intimitat d'aquestes famílies sense casa. Mobles modestos, taules, cadires, llits, matalassos, pilots de roba, un piano sense la tapa davantera, com avergonyit d'ensenyar la nuesa de les sever entranyes de cordes, un altre piano de tecles groguenques, làmpades amb pantalles de pergamí o de cretona, litografies, llibres i retrats. Mobles amuntegats al carrer, a punt per a traslladar-los a les noves residències; altres que encara resten dintre de les cases en ruïnes, perquè de tan atrotinats que són, més val ja no preocupar-se'n. Un quadre de destrucció de cases sòrdides i mobles vells. (Pi i Sunyer 2006: 164-165) ${ }^{16}$.

Otro asunto es el de los refugios antiaéreos, tratados en las notas Una altra festa, Onze de setembre y Conversa al refugi, donde se destaca la experiencia y la vivencia en los mismos. En la primera nota cuenta uno de los bombardeos más intensos que sufre Londres, las bombas caían cerca de la vivienda donde reside con sus hijos. De este modo el autor narra las sensaciones que tiene durante esos ataques, mientras, una vez más, intenta mostrar la tranquilidad de la vida cotidiana:

Després d'un sopar neguitós, ritmat amb l'acompanyament desagradable de la música botzinadora dels motors i a cops de timbals de les bombes, hem baixat una estona a l'abric de les galeries dels soterranis de la casa, que diuen que serveixen de refugi. Però es fa molt incòmode d'estar-hi. Érem molts; jo m'he assegut en una petita capsa d'embalatge, altres estaven drets, el lloc no és tampoc gaire segur. El marge de tranquil litat només relativa que dóna no compensa, quan es perllonga l'alarma, les molèsties de l'estada. Així doncs, després d'haver parlat una mica i llegit una estona, i sense que l'acte representés per part nostra cap mostra d'heroisme, hem decidit tornar a dalt i ficar-nos al llit, que, fet i fet, com que bé prou pateixen els nervis i els cors tocats, més val jeure que arrossegar-se hores i hores d'un mal seient a un altre de pitjor. (Pi i Sunyer 2006: 200)

En Onze de setembre, otra nota dedica a esos refugios, describe el espacio que les correspondía a ellos: «un tros de corredor que té al llarg d'una paret un rengle d'armaris-carboneres» (Pi i Sunyer 2006: 203; v. 208). Asimismo, narra cómo deberían de vivir allí: «les dones van gairebé totes amb pantalons i jerseis. Per les diverses galeries, aprofitant qualsevol racó, hi ha gent damunt de gandules, de cadires allargades, de matalassos de goma, de pilots de coixins, mantes i abrics» (Pi i Sunyer 2006: 203).

Por último, el asunto de los bomberos se desarrolla en dos notas: El local dels vigilants y Fire-watchers (Pi i Sunyer 2006: 211-214, 215-220). La actividad de esos profesionales es importante en aquellos momentos, incluso habiéndose ofrecido el propio Carles Pi i Sunyer para esa labor.

Otro tema presente en sus notas es la relación de la Segunda Guerra Mundial y la Guerra Civil. Carles Pi i Sunyer plantea en La significació del moment (Pi i Sun-

16 Véase también en la nota Impressions del moment del volumen Londres en guerra... (Pi i Sunyer 2006: 180-181, 186); o en el libro Aquell verd anglès ( $\mathrm{Pi}$ i Sunyer 1977: 43-44, 47-48, 70, 107). 
yer 1992: 13-17) y en Més val tenir raó que no pas guanyar (Pi i Sunyer 1992: 6064) -dos textos del volumen Vuits escrits d'exili- que la Guerra Civil española fue antesala del conflicto mundial. En ese espectro, el autor advierte que doblemente «Catalunya ha estat víctima d'una agressió que era com una primera ratxa resseca de la gran ventada totalitària; la guerra civil espanyola no fou més que un antecedent de la guerra civil europea» (Pi i Sunyer 1992: 62-63, véase también 15). Por su parte, en las notas dedicadas al mismo tema que aparecen en el volumen Londres en guerra..., esta comparación la encontramos junto a sus primeras referencias sobre la ya mencionada normalidad de la sociedad británica:

Semblava que, per a viure tranquil, ignorat, indiferent a tot, bastava tancar-se a casa, recloure l'esperit, renunciar...; i ara hom veu que no és així, que és la mateixa vida, el benestar senzill, allò que cal defensar asprament, dolorosament; que cal combatre coratjosament per a no perdre'ls. Nosaltres ja ho havíem après en l'agonia d'un sofrir sense esperança; el nostre poble en porta les ferides sagnants a la carn martiritzada. (Pi i Sunyer 2006: 44)

En otras ocasiones, Carles Pi i Sunyer no solo evoca la Guerra Civil a través de los recuerdos de un antiguo combatiente de las Brigadas Internacionales (Pi i Sunyer 2006: 64-65), sino que también aporta críticas a la política del Régimen franquista, como se pueden ver en No hi aneu!, texto también proveniente de Vuit escrits d'exili... (Pi i Sunyer 1992: 90-95), más concretamente por el envío de tropas al frente ruso. A estos voluntaris -entiéndase el término en tono irónico y además referido a jóvenes catalanes- el autor les indica desde el exilio que «aquesta vegada [luchan] no per defensar la terra i la pàtria, el seu i els seus; sinó per a combatre lluny de casa, a terres inconegudes, per a lluitar pels altres i, pitjor encara, pels seus enemics, pels culpables de tots els dolors que han sofert» (Pi i Sunyer 1992: 92); y les exhorta: «És davant d'aquesta contingència que cal dir a la joventut catalana: No hi aneu! I si us hi veiéssiu obligats a anar-hi, feu-ho, allà on sigui i com sigui, amb la ferma i preconcebuda decisió de no combatre pels vostres enemics i contra Catalunya» (Pi i Sunyer 1992: 93).

Asimismo, en las notas dedicadas a los bombardeos, compara estos con los que vivió en Barcelona y analiza la sensación que provocaron en la población, comentando que el ataque no le «podria [...] reservar-me poques emocions inèdites, perquè si d'una banda ací era major la intensitat i durada de l'atac, per l'altra, a la nostra ciutat, hi havia el descoratjament que dóna la indefensió en què sempre va trobarse» (Pi i Sunyer 2006: 191) ${ }^{17}$.

En cuanto a la cultura y la guerra como tema, lo encontramos en cuatro notas: Estiu de guerra, Alarma a la biblioteca, Mentre sentiem Wagner y Art en temps de guerra. Estos textos, que nos llevan de la Biblioteca del Museo Británico a un concierto wagneriano que permite todo tipo de reconsideraciones germánicas, insisten

\footnotetext{
17 Véase también en el volumen Aquell verd anglès las páginas que dedica a los sentimientos de las personas cuando son bombardeadas (Pi i Sunyer 1977: 85-86).
} 
en mostrar la tranquilidad que vive la sociedad inglesa y su filosofía de que la vida sigue adelante ( $\mathrm{Pi}$ i Sunyer 2006: 86-90). Al autor le llama la atención cómo se valora la cultura, por ejemple cuando «es van evacuar els quadres de la National Gallery per a fer-ne una sala de concerts. Prosperaven els diaris i, malgrat una seriosa manca de paper, l'editorial Penguin continuava traient una oferta molt variada de llibres» (Pi-Sunyer i Cuberta 2006: 32).

\section{Bibliografía}

\section{a. Corpus:}

PI i SUNYER, Carles (1975): La República y la guerra: memorias de un político catalán. México: Oasis.

- (1977): Aquell verd anglès. Barcelona: Pòrtic.

- (1992): Vuit escrits d'exili (1939-1941). Barcelona: Fundació Carles Pi i Sunyer d'Estudis Autonòmics i Locals.

- (2000): 1939. Memòries del primer exili. Barcelona: Fundació Carles Pi i Sunyer d'Estudis Autonòmics i Locals.

- (2006): Londres en guerra, 1939-1942. Impressions d'un exiliat. Barcelona: Fundació Pi i Sunyer.

\section{b. Teoría, historia y crítica:}

ARTís-GENER, Avel·lí (1975): La diáspora republicana. Traduc. Francisco Ruiz Camps. Barcelona: Euros.

- (1989-1996): Viure i veure. Barcelona: Pòrtic.

CAMPILlO, Maria (1988): «El conte: Pere Calders» en Història de la literatura catalana (dir. J. Molas), vol. XI, pp. 12-29. Barcelona: Ariel.

CASTEllanos, Jordi (2011): «L'ombra de l'atzavara: un viatge especial a l'alteritat» en Llegir l'exili, pp. 223-236. Barcelona: L'Avenç.

FERNÁNDEZ, Álvaro (2003): «Corazón: polaco; Literaturización de la memoria en Marías y Muñoz Molina». [En línea] $V^{o}$ Congreso Internacional Orbis Tertius de Teoria y Crítica Literaria, 13 al 16 de agosto de 2003. La Plata: Polémicas literarias, críticas y culturales. Disponible en:

http://www.fuentesmemoria.fahce.unlp.edu.ar/trab_eventos/ev.12/ev.12.pdf

FERNÁNDEZ PozA, Óscar (2015): «Avel·lí Artís i Balaguer (1881-1954), narrador». Revista de Lenguas y Literaturas Catalana, Gallega y Vasca 20: 59-70.

FERNÁNDEZ PozA, Óscar y RIBERA LLOPIS, Juan M. (2011): «Fuentes para el estudio del exilio literario catalán en Hispanoamérica». Revista de Filología Románica. Anejo VII. Escrituras del exilio: 115-127.

FONTSERÈ, Carles (1999): Un exiliat de tercera: a París durant la Segona Guerra Mundial. Barcelona: Proa.

- (2004): Un exiliado de tercera: en París durante la Segunda Guerra Mundial. Barcelona: Acantilado. 
GuILlAmON, Julià (2008): El dia revolt. Literatura catalana de l'exili. Barcelona. Editorial Empúries.

MADRENAS, Dolors y RIBERA, Juan M. (2002): «Les novel-listes del anys 20 i 30 i la memòria novel-lada: Rosa Maria Arquimbau (1910-1992)» en Memòria i Literatura. La construcció del subjecte femení. Periodisme i Literatura, pp. 125-134. Alacant/València: Editorial Denes.

PI-SUNYER i CUBERTA, Oriol (2006): «Pròleg» in Londres en guerra, 1939-1942. Impressions d'un exiliat, pp. 9-33, traduc. Susan M. DiGiacomo. Barcelona: Fundació Pi i Sunyer.

RiQUER, Borja de (2013): «Pròleg: de Valls a Mèxic, passant per Montserrat, França i Suïssa», en Dues guerres $i$ un exili, pp. 7-16. Barcelona: L'Avenç.

VILANOVA, Frances (1992): «Nota a l'edició» in Vuit escrits d'exili (1939-1941), pp. 7-11. Barcelona: Fundació Carles Pi i Sunyer d'Estudis Autonòmics i Locals. 